\title{
S-carboxymethylcysteine normalises airway responsiveness in sensitised and challenged mice
}

\author{
K. Takeda*, N. Miyahara*, T. Kodama*, C. Taube*, A. Balhorn*, A. Dakhama*, \\ K. Kitamura\#, A. Hirano" ${ }^{\#}$ M. Tanimoto ${ }^{\#}$ and E.W. Gelfand*
}

ABSTRACT: S-carboxymethylcysteine (S-CMC) has been used as a mucoregulator in respiratory diseases. However, the mechanism of action of S-CMC on allergic airway inflammation has not yet been defined.

In the present study, BALB/c mice were initially sensitised and challenged to ovalbumin (OVA) and, weeks later, re-challenged with OVA (secondary challenge). S-CMC (5-100 $\mathrm{mg} \cdot \mathrm{kg}^{-1}$ ) was administered from 2 days before the secondary challenge through to the day of assay.

Mice developed airway hyperresponsiveness (AHR) $6 \mathrm{~h}$ after the secondary challenge and increased numbers of neutrophils were present in the bronchoalveolar lavage (BAL) fluid. At 72 h after secondary challenge, mice again developed AHR, but the BAL fluid contained large numbers of eosinophils. S-CMC treatment was found to reduce AHR and neutrophilia at $6 \mathrm{~h}$, as well as eosinophilia and AHR at $72 \mathrm{~h}$. These effects appeared to be dose dependent. Goblet cell hyperplasia, observed at $72 \mathrm{~h}$, was reduced by S-CMC. In BAL fluid, increased levels of interferon$\gamma$, interleukin (IL)-12 and IL-10 and decreased levels of IL-5 and IL-13 were detected.

In conclusion, the data indicate that $S$-carboxymethylcysteine is effective in reducing airway hyperresponsiveness and airway inflammation at two distinct phases of the response to the secondary allergen challenge in sensitised mice.

KEYWORDS: Airway hyperresponsiveness, eosinophils, neutrophils, S-carboxymethylcysteine

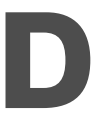
espite significant advances in asthma therapeutics since the 1990s, morbidity and mortality remain a worldwide concern [1]. In the pathogenesis of asthma, various types of inflammatory cells are thought to play an important role in the development of airway hyperresponsiveness (AHR) and allergic airway inflammation. A common theory is that the disease is the result of chronic airway inflammation, largely dependent upon eosinophils, leading to AHR and reversible airway obstruction $[2,3]$. With the rising incidence and therapeutic insufficiencies, it is now more apparent that asthma is a heterogeneous syndrome, with numerous cell types and mediators contributing to the disease phenotype. Central to the pathogenesis of the airway disease are antigen-specific, memory T-cell responses and, perhaps to a lesser degree, antigenspecific immunoglobulin E responses [4, 5].

Conversely, mucus hypersecretion is one of the major symptoms in asthmatics and has been related to fatal asthma pathogenesis [6]. Although the contribution of mucus production on asthmatic airways is still unclear, MUC5AC and other mucin genes have been shown to be related to asthma status in clinical studies [7] and in animal models [8]. S-carboxymethylcysteine (S-CMC) has been used as a mucoregulator for treating chronic obstructive pulmonary disease (COPD), asthma and chronic nasal diseases, such as chronic sinusitis or otitis media, with some efficacy [9-11]. However, there have been few studies addressing potential efficacy or mechanism of action in allergen-induced asthma. KATAYAMA et al. [12] showed that S-CMC decreased cough sensitivity, but not AHR in an antigen-induced guinea pig model, and AsTi et al. [13] showed a suppressive effect on cigarette smoke-induced AHR. S-CMC is known to suppress neutrophil chemotaxis in vitro as well as in vivo $[13,14]$. At early time points after allergen challenge, an increase in numbers of neutrophils in the airways has been shown to accompany changes in airway function [15]. However, it appears that depletion of neutrophils may have little effect on allergic airway eosinophilic inflammation or AHR [16].

\section{AFFILIATIONS}

*Dept of Paediatrics, National Jewish Medical and Research Center, Denver, CO, USA.

\# Okayama University Medical School, Okayama, Japan.

CORRESPONDENCE

E.W. Gelfand

1400 Jackson Street

Denver

CO 80206

USA

Fax: 13032702105

E-mail: gelfande@njc.org

Received:

July 302004

Accepted after revision:

June 102005

SUPPORT STATEMENT

This study was supported by National Institute of Health grants HL-36577,

HL-61005 and, in part, by Kyorin

Pharmaceuticals (Tokyo, Japan). 
In the present study, a murine model was utilised, which distinguishes a neutrophil-dominant phase early after antigen challenge and an eosinophil-dominant phase with few neutrophils at later time points. Both phases are associated with AHR. To determine if $S$-CMC can modulate these two phases of the inflammatory response, reagents were administrated prior to secondary challenge and changes in airway inflammation and AHR were monitored.

\section{MATERIALS AND METHODS Animals}

Female BALB/c mice aged 6-8 weeks old were obtained from Jackson Laboratories (Bar Harbor, ME, USA). The animals were maintained on an ovalbumin (OVA)-free diet. Experiments were conducted under a protocol approved by the Institutional Animal Care and Use Committee of the National Jewish Medical and Research Center (Denver, CO, USA).

\section{Experimental protocol}

The experimental protocol for sensitisation and challenge to allergen was modified from previously described procedures [17]. Briefly, mice were sensitised by i.p. injection of $10 \mu \mathrm{g}$ of OVA (Grade V; Sigma Chemical Co., St. Louis, MO, USA) emulsified in $2.25 \mathrm{mg}$ aluminium hydroxide (AlumImuject; Pierce, Rockford, IL, USA) in a total volume of $100 \mu \mathrm{L}$ on days 1 and 7 . Mice were challenged (primary) via the airways with OVA $(0.2 \%$ in saline) for $20 \mathrm{~min}$ on days 14,15 and 16 by ultrasonic nebuliser (model NE-U07; Omron Healthcare, Vernon Hills, IL, USA). On day 30, mice received a single secondary challenge via the airways with $1 \%$ OVA for $20 \mathrm{~min}$. Control
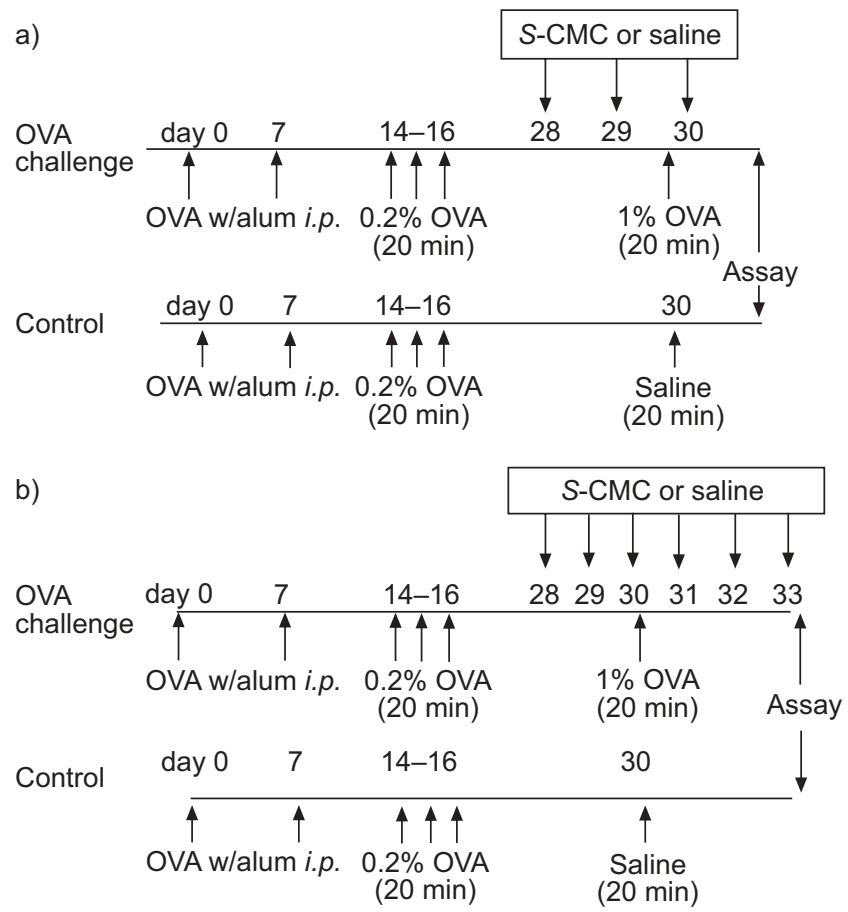

FIGURE 1. Diagram to show the experimental protocol a) $6 \mathrm{~h}$ and b) $72 \mathrm{~h}$ after the secondary challenge. S-CMC: S-carboxymethylcysteine; OVA: ovalbumin; w/alum: with aluminium hydroxide. mice received saline as the secondary challenge. Mice were studied $6 \mathrm{~h}$ and $72 \mathrm{~h}$ (fig. 1) after the secondary challenge.

To determine the effects of $S$-CMC on airway allergic inflammation and AHR, 5, 10 or $100 \mathrm{mg} \cdot \mathrm{kg}^{-1}$ of $S-C M C$ was

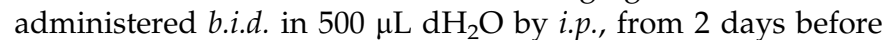
the secondary challenge through to the day of study. Control groups of mice received saline in the same fashion. S-CMC was provided by Kyorin Pharmaceuticals (Tokyo, Japan).

\section{Determination of airway responsiveness}

Airway responsiveness was assessed as changes in airway function after challenge with aerosolised methacholine (MCh; Sigma). Mice were anaesthetised, tracheostomised and mechanically ventilated with lung function assessed as described previously [18]. Ventilation was achieved at 160 breaths $\cdot \mathrm{min}^{-1}$ at a tidal volume of $0.16 \mathrm{~mL}$ with a positive endexpiratory pressure of $2-4 \mathrm{cmH}_{2} \mathrm{O}$. Lung resistance $(R \mathrm{~L})$ was continuously computed (Labview, National Instruments, TX, USA) by fitting flow, volume and pressure to an equation of motion using a recessive least squares algorithm.

Aerosolised MCh was administered through bypass tubing via an ultrasonic nebuliser (model 5500D; DeVilbiss, Somerset, PA, USA) placed between the expiratory port of the ventilator and the four-way connector. Aerosolised MCh was administered for $8 \mathrm{~s}$ with a tidal volume of $0.45 \mathrm{~mL}$ and frequency of 60 breaths $\cdot \min ^{-1}$ using another ventilator (model 683; Harvard Apparatus, South Natick, MA, USA). The data of RL was continuously collected for up to $3 \mathrm{~min}$ and maximum values were taken. PC200 values (MCh concentration required to induce a $200 \%$ change in $R \mathrm{~L}$ relative to saline) were also calculated.

\section{Bronchoalveolar lavage}

Immediately after assessment of AHR, lungs were lavaged via the tracheal tube with Hank's balanced solution (HBSS; $\left.1 \times 1 \mathrm{~mL}, 37^{\circ} \mathrm{C}\right)$. The volume of collected bronchoalveolar lavage (BAL) fluid was measured in each sample and the number of leukocytes was counted (Coulter Counter; Coulter Corporation, Hialeah, FL, USA). Differential cell counts were performed by counting at least 200 cells on cytocentrifuged preparations (Cytospin 3; Shandon Ltd, Runcorn, UK). Slides were stained with modified Wright-Giemsa and white blood cells were differentiated by standard haematological procedures in a blinded fashion. BAL fluid supernatants were collected and stored at $-70^{\circ} \mathrm{C}$ until measurement.

\section{Cell preparation for in vitro cytokine production}

To determine the effect of S-CMC on cytokine production at the single cell level, cells were isolated and cultured with different concentrations of OVA and S-CMC. Spleen, peribronchial lymph nodes and lungs were taken from mice $72 \mathrm{~h}$ after secondary challenge. Mononuclear cells from spleen and peribronchial lymph node (PBLN) were isolated. Lung mononuclear cells were obtained following collagenase digestion and gradient centrifugation (35\% Percoll (Sigma)) to remove epithelial cells. Cells in BAL fluid were collected following saline challenge and instillation of $1 \mathrm{~mL}$ of HBSS four times. To purify airway macrophages, BAL cells were cultured in plastic dishes at $37^{\circ} \mathrm{C}$ for $1 \mathrm{~h}$ followed by washing three times with $37^{\circ} \mathrm{C}$ HBSS. Adhesive cells were collected and shown to be 
$>95 \%$ macrophages. Spleen, PBLN and lung cells $\left(2 \times 10^{5}\right)$ and alveolar macrophages $\left(1 \times 10^{5}\right)$ were cultured either with or without $10 \mu \mathrm{g} \cdot \mathrm{mL}^{-1}$ of OVA. S-CMC was added to cultures at concentrations of $0,1,10$ and $100 \mu \mathrm{g} \cdot \mathrm{mL}^{-1}$. After $24 \mathrm{~h}$ incubation at $37^{\circ} \mathrm{C}$, supernatants were collected.

\section{Measurement of cytokines}

Cytokine levels in the BAL fluid or supernatants from cell culture were measured as previously described [19]. Briefly, measurements of interleukin (IL)-4, IL-5, IL-10 and IL-12 were performed by ELISA (BD PharMingen, San Diego, CA, USA) with 96-well plates (Immulon 2; Dynatech, Chantilly, VA, USA). IL-13 measurements were performed using an ELISA kit (QuantikineM; R\&D Systems, Minneapolis, MN, USA), all following the manufacturers protocol. The limits of detection were: $1.5 \mathrm{pg} \cdot \mathrm{mL}^{-1}$ for IL-13; $4 \mathrm{pg} \cdot \mathrm{mL}^{-1}$ for IL-4 and IL-5; and $10 \mathrm{pg} \cdot \mathrm{ml}^{-1}$ for IL-10 and interferon (IFN)- $\gamma$.
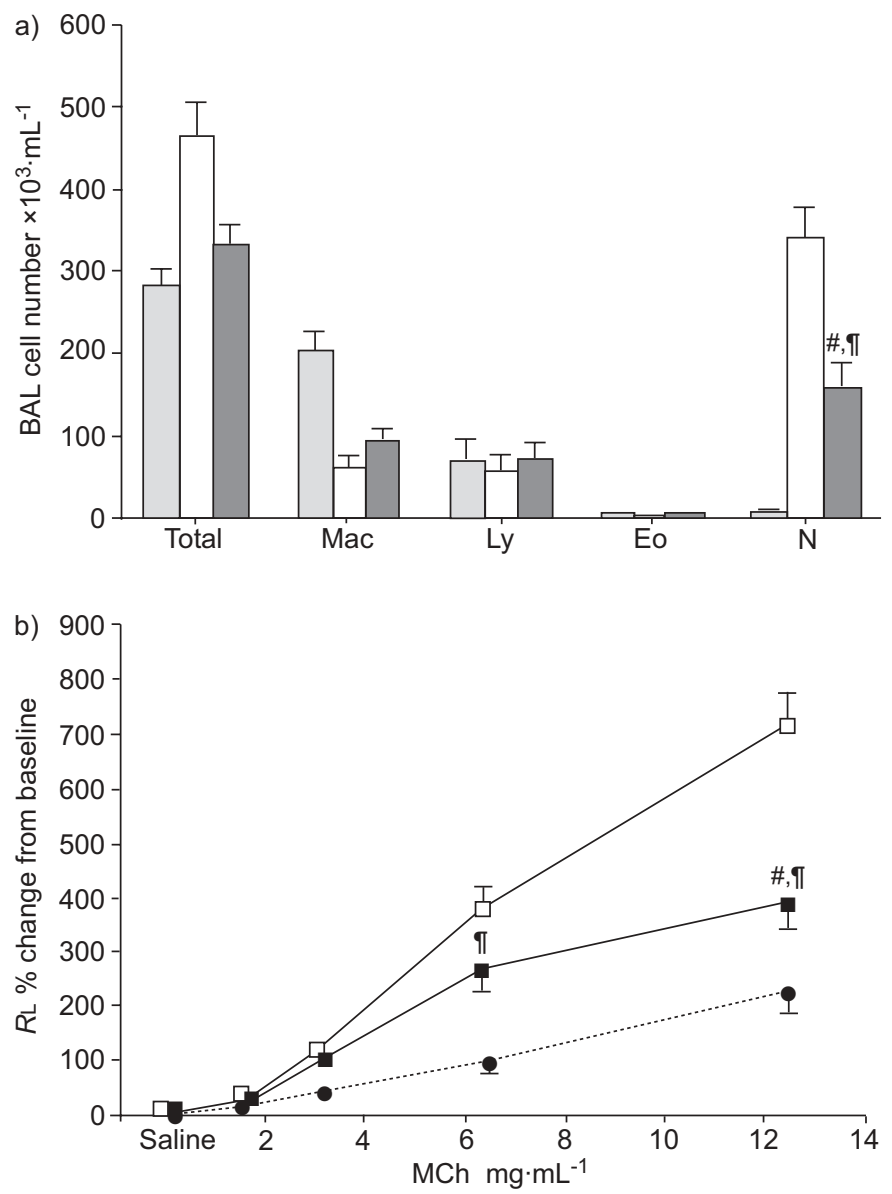

FIGURE 2. a) Cell composition in bronchoalveolar lavage (BAL) fluid obtained $6 \mathrm{~h}$ after secondary challenge. $\square$ : control; $\square$ : saline; $\square$ : S-carboxymethylcysteine (S-CMC). Mac: macrophage; Ly: lymphocyte; Eo: eosinophil; N: neutrophil numbers. b) Changes in lung resistance $(R L) 6 \mathrm{~h}$ after secondary challenge. $R \mathrm{~L}$ values were obtained in response to increasing concentrations of inhaled methacholine (MCh). $\square$ : saline challenge; $\mathbf{\square}$ : S-CMC treatment during secondary ovalbumin (OVA) challenge; $\bullet$ : control (saline) treatment during secondary OVA challenge. $n=8 .{ }^{*}: p<0.05$ significant difference between the saline treatment and $S$-CMC treatment group; \%: $p<0.05$ significant difference between the saline challenge and $S-C M C$ treatment groups.

\section{Histological studies}

Lungs were inflated through the trachea with $1 \mathrm{~mL}$ of $10 \%$ formalin and fixed in $10 \%$ formalin by immersion. Blocks of lung tissue were cut around the main bronchus and embedded in paraffin. Sections $(6 \mu \mathrm{m})$ were cut and stained with haematoxylin-eosin (HE) to analyse inflammatory cell infiltration. For detection of mucus-containing cells in formalin-fixed airway tissue, sections were stained with periodic acid-Schiff (PAS) and counterstained with HE. Cells containing eosinophilic major basic protein (MBP) were identified by immunohistochemical staining as previously described using rabbit-anti-mouse MBP (provided by J.J. Lee, Mayo Clinic, Scottsdale, AZ, USA) [20]. The slides transferred to pictures using a Nikon microscope (Melville, NY, USA) equipped with a fluorescein filter system. PAS-positive cells and numbers of peribronchial eosinophils in the tissues were quantified using an NIH Image analysis system (version 1.63; NIH, Bethesda, MA, USA) and counting 6-8 different fields per slide in a blinded manner.
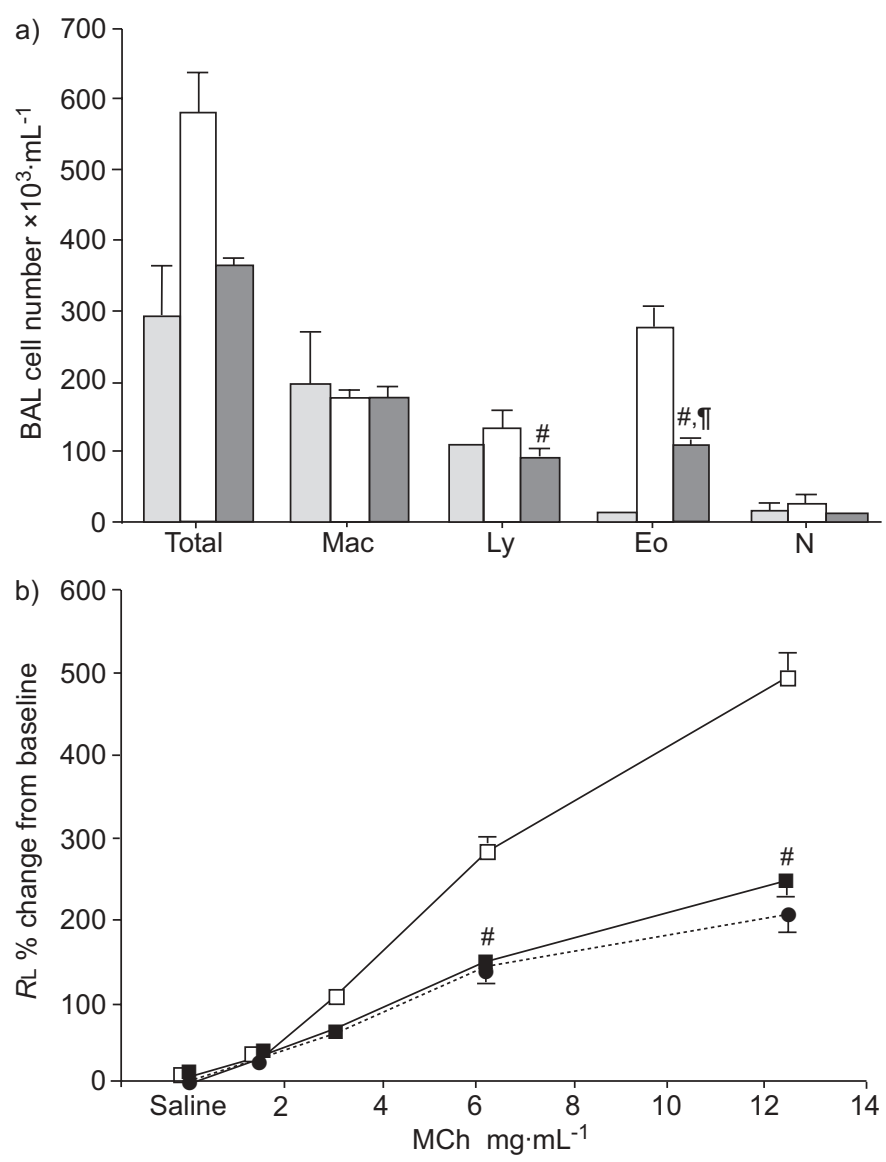

FIGURE 3. a) Cell composition in bronchoalveolar lavage (BAL) fluid obtained $72 \mathrm{~h}$ after secondary challenge. $\mathbf{w}^{-}$: control; $\square$ : saline; $\mathbf{\square}$ : S-carboxymethylcysteine (S-CMC). Mac: macrophage; Ly: lymphocyte; Eo: eosinophil; N: neutrophil numbers. b) Changes in lung resistance $(R L) 72 \mathrm{~h}$ after secondary challenge. $\square$ : saline challenge; $\mathbf{\square}$ : $\mathrm{CMC}$ treatment during secondary ovalbumin (OVA) challenge; $\bullet$ : control (saline) treatment during secondary OVA challenge. $n=8$. \#: $p<0.05$ significant difference between the saline treatment and $S$-CMC treatment groups; $\uparrow: p<0.05$ significant difference between the saline challenge and S-CMC treatment groups. 


\section{Statistical analysis}

All results were expressed as mean \pm SEM. ANOVA was used to determine the levels of difference between all groups. Groups were compared by unpaired two-tailed t-test. For analysis of IL-10 levels in alveolar macrophage cultures, the MannWhitney U-test was used. The p-value for significance was set at 0.05 .

\section{RESULTS}

\section{Neutrophilic airway inflammation and AHR $6 h$ after} secondary challenge

Allergen-challenged, but not saline-challenged mice, showed a neutrophil-dominant inflammatory response in the BAL fluid (75\% of total BAL fluid cells; fig. 2a) and AHR in response to inhaled MCh $6 \mathrm{~h}$ after secondary challenge (fig. $2 \mathrm{~b}$ ). When mice were treated with $S-C M C$, the numbers of neutrophils were decreased by $\sim 50 \%$ and airway responsiveness to $\mathrm{MCh}$ was also decreased significantly compared with saline-treated mice.

\section{Eosinophilic airway inflammation and AHR $72 \boldsymbol{h}$ after secondary challenge}

The mice developed an eosinophil-dominant inflammatory response $72 \mathrm{~h}$ after secondary challenge in the BAL fluid $(45 \%$
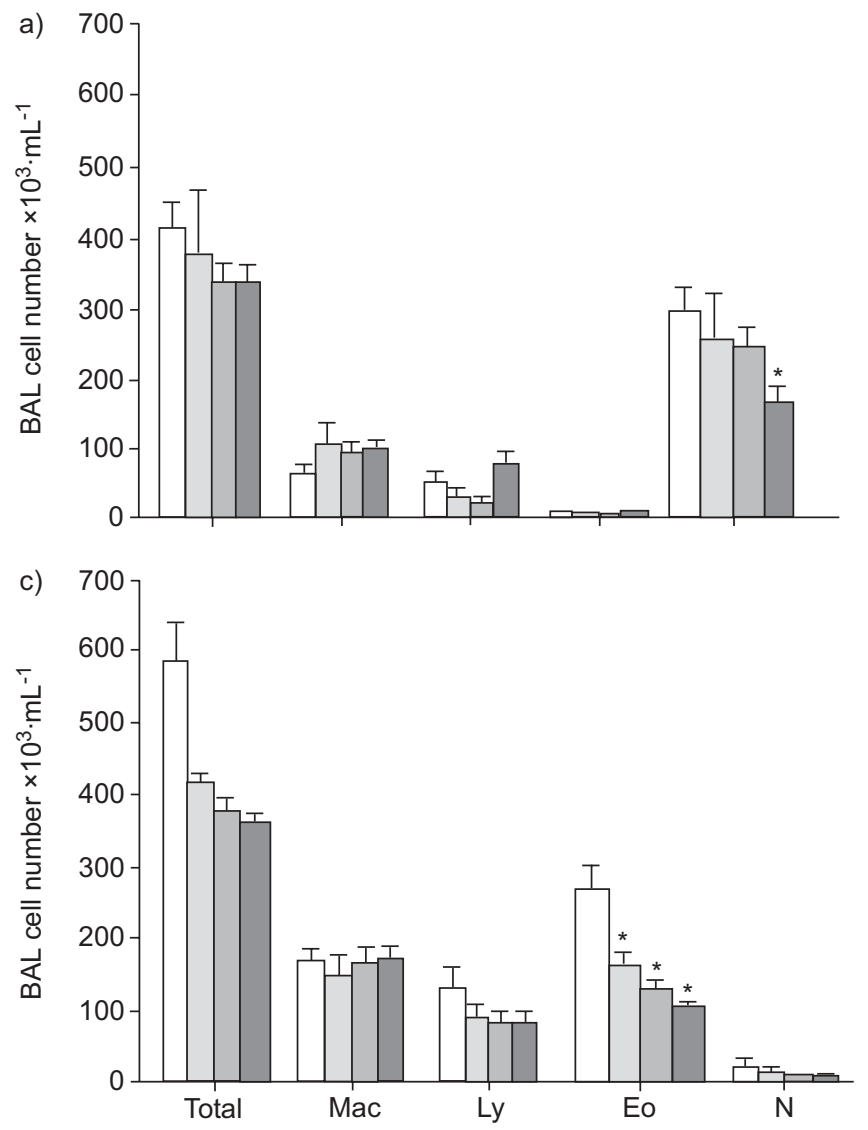

of total BAL fluid cells), few neutrophils (fig. 3a) and AHR to inhaled MCh (fig. 3b). When S-CMC was administered, the numbers of eosinophils in BAL fluid were significantly decreased to $\sim 37 \%$ of the control group, and airway responsiveness was reduced to the same levels as saline-challenged mice.

\section{S-CMC dose-dependent effects on the airway}

To determine if the effects of S-CMC were dose-dependent, 5, 10 and $100 \mathrm{mg} \cdot \mathrm{kg}^{-1}$ of $S$-CMC were administered to mice. AHR and BAL cell composition were investigated at 6 or $72 \mathrm{~h}$ after secondary allergen challenge. Only $100 \mathrm{mg} \cdot \mathrm{kg}^{-1}$ of $S-C M C$ was effective in reducing neutrophil numbers in BAL fluid $6 \mathrm{~h}$ after secondary challenge (fig. $4 \mathrm{a}$ and b). In parallel, and only at $100 \mathrm{mg} \cdot \mathrm{kg}^{-1}, \mathrm{~S}$-CMC was effective in reducing AHR resulting in a significant increase in PC200 values in airway resistance. Lower doses of S-CMC $\left(5,10\right.$, and $\left.100 \mathrm{mg} \cdot \mathrm{kg}^{-1}\right)$ resulted in a dose-dependent decrease in eosinophil numbers in the BAL fluid as well as a dose-dependent increase in PC200 values for airway resistance $72 \mathrm{~h}$ after secondary challenge (fig. $4 \mathrm{c}$ and $\mathrm{d}$ ).

\section{Histological analysis}

Histological studies monitoring HE, PAS and anti-MBP staining were performed on lungs removed from the same
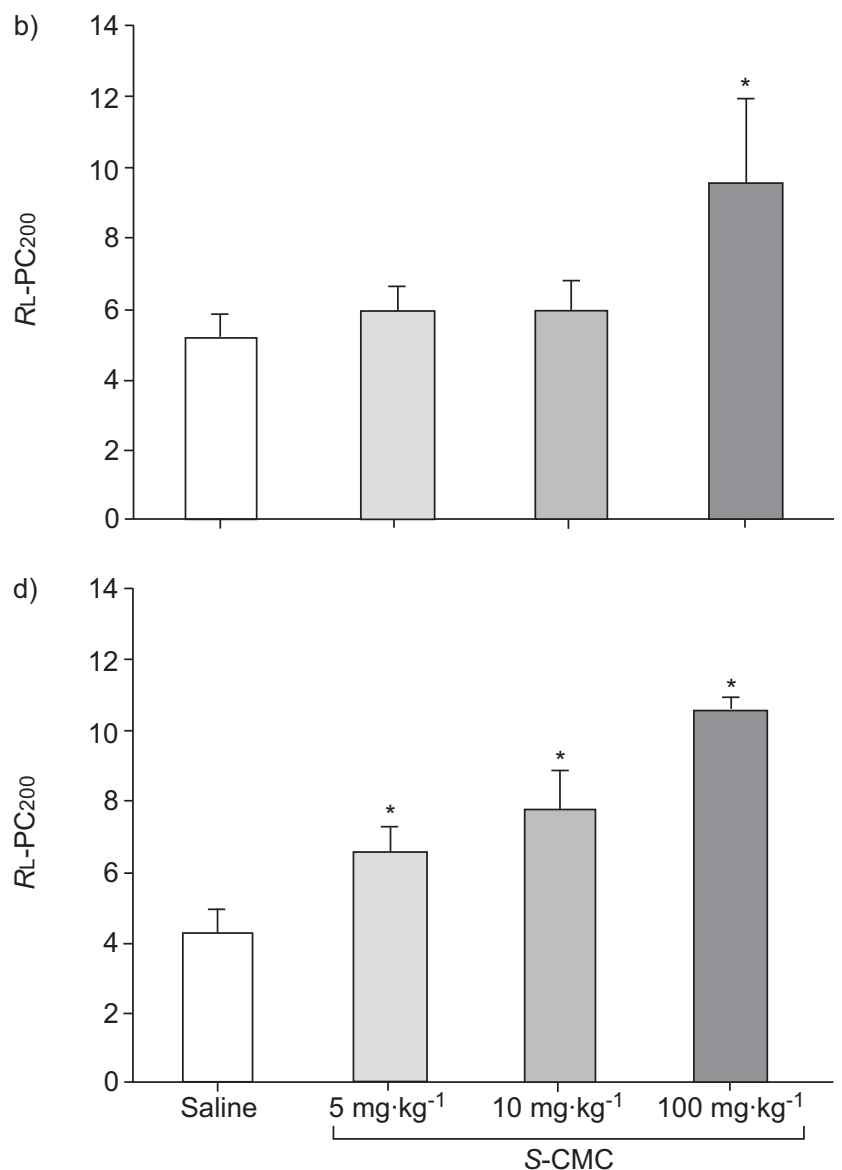

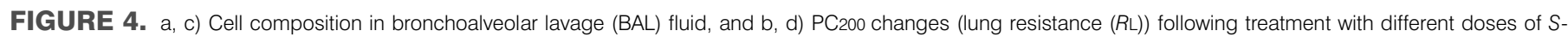

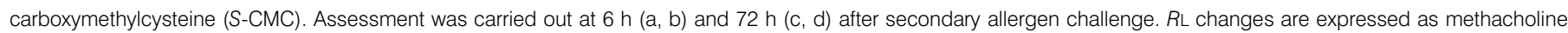

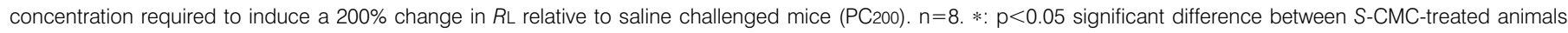
versus saline-treated animals. 

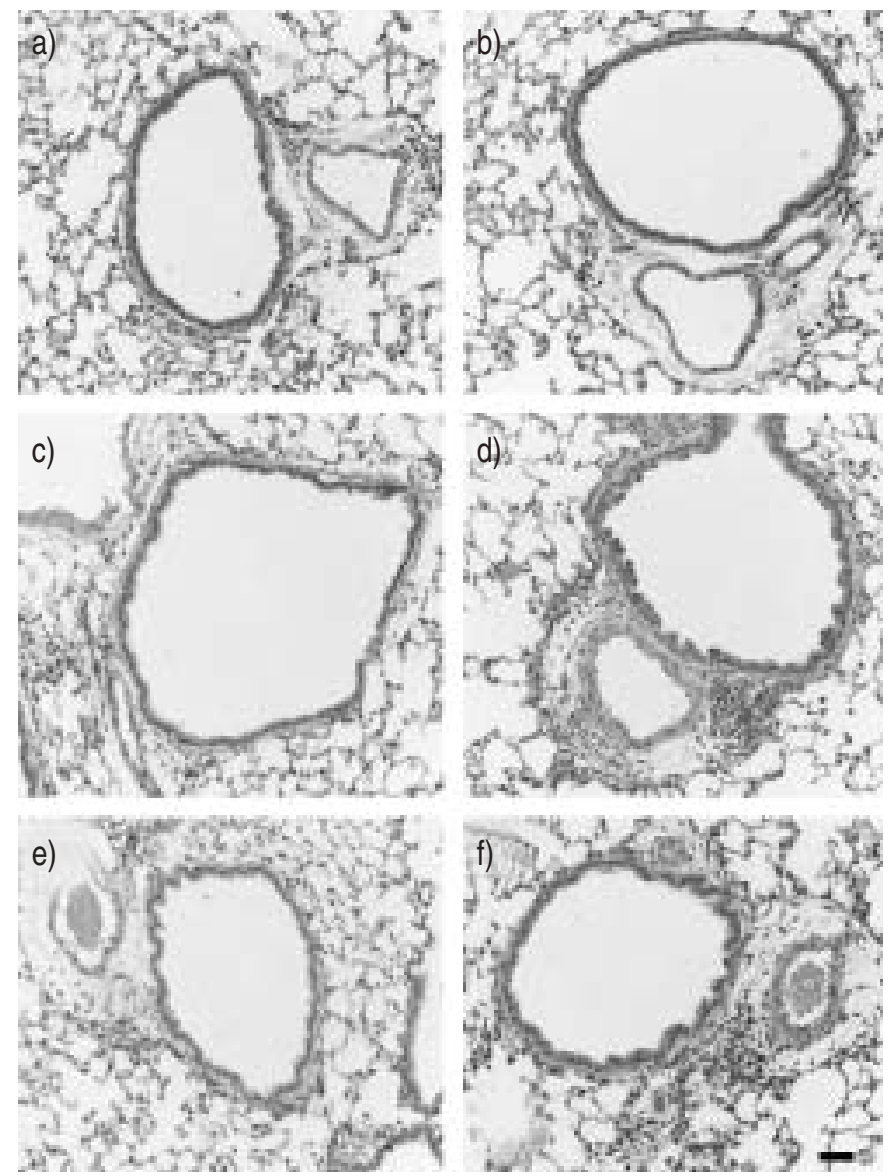

FIGURE 5. Sections of lung tissue were prepared $6 \mathrm{~h}$ after secondary challenge ( $\mathrm{a}, \mathrm{c}$ and $\mathrm{e}$ ), and $72 \mathrm{~h}$ after secondary challenge (b, $\mathrm{d}$ and $\mathrm{f}$ ), both with haemoxylin and eosin staining. The slides show saline challenge $(a, b)$, secondary allergen challenge with saline treatment (c, d) and secondary allergen challenge following S-carboxymethylcysteine treatment (e, f). Scale bar $=50 \mu \mathrm{m}$.

animals described previously. In OVA-sensitised mice, cell infiltration into the peribronchial regions was detected $72 \mathrm{~h}$ after secondary challenge (fig. 5). Few cells were observed in the peribronchial regions $6 \mathrm{~h}$ after secondary challenge, although increased numbers of neutrophils were observed in the alveolae. In the HE-stained sections, no obvious differences between S-CMC-treated and saline-treated mice were observed at any time point.

PAS-stained sections showed goblet cell hyperplasia and mucus hyperproduction $72 \mathrm{~h}$ after secondary challenge (fig. 6a-d), but not $6 \mathrm{~h}$ after challenge (data not shown). Following S-CMC treatment, PAS-positive cells were reduced significantly compared with saline-treated mice (fig. 6).

Anti-MBP staining of lung sections revealed the localisation of eosinophils in the tissue. At $72 \mathrm{~h}$ following secondary challenge, a significant accumulation of eosinophils in the peribronchial regions was observed (fig. 7a-f). Quantification of MBP-positive cells (eosinophils) revealed a small increase $6 \mathrm{~h}$ after secondary challenge, but a marked increase $72 \mathrm{~h}$ after the secondary challenge in the peribronchial regions (fig. $7 \mathrm{~g}$ ). This eosinophilic infiltration at $72 \mathrm{~h}$ was significantly reduced with S-CMC treatment.
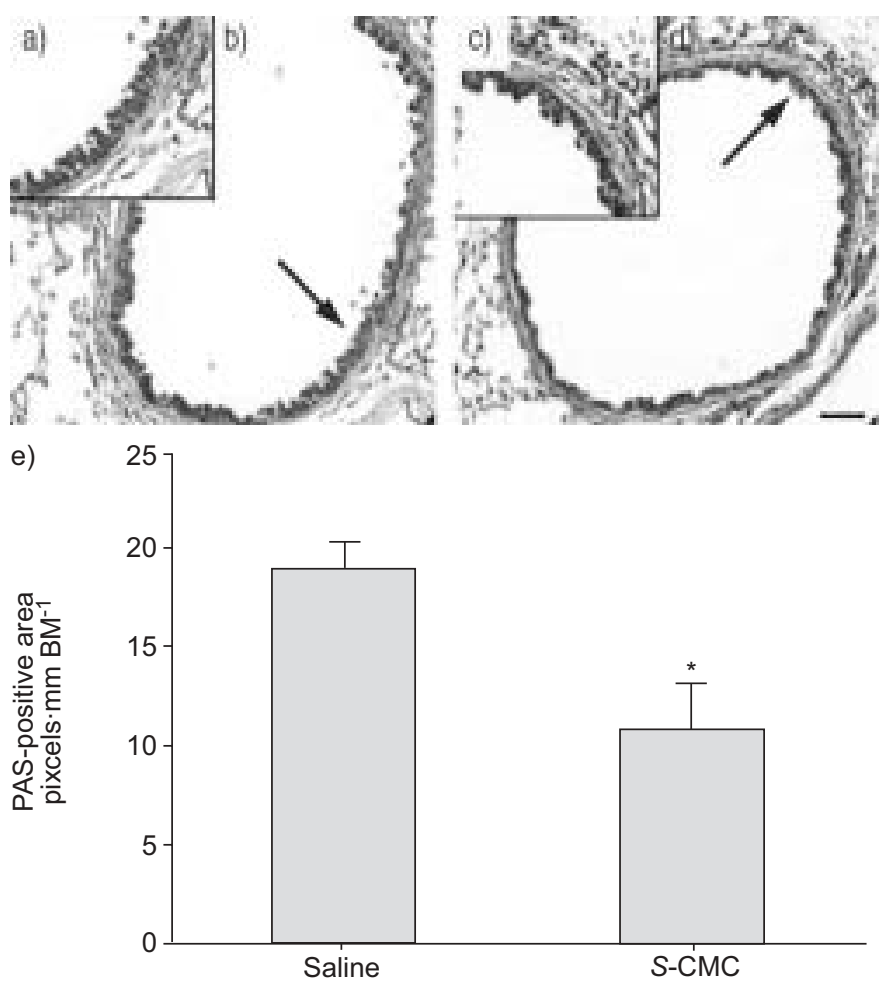

FIGURE 6. Assessment of goblet cell hyperplasia and mucin hyperproduction, using periodic acid-Schiff (PAS) and haemoxylin and eosin as a counter stain. Sections were prepared $72 \mathrm{~h}$ after secondary challenge following: $\mathrm{a}, \mathrm{b}$ ) saline, or $\mathrm{c}$, d) S-carboxymethylcysteine (S-CMC) treatment (a and $c$ are enlarged areas of b and $\mathrm{d}$, respectively). e) Goblet cell hyperplasia $72 \mathrm{~h}$ after secondary allergen challenge was quantified in PAS-stained sections and expressed per $\mathrm{mm}$ of basement membrane (BM). $n=6 .{ }^{*}: p<0.05$ significant difference between $S-C M C$ treatment versus saline. Scale bar $=50 \mu \mathrm{m}$

\section{Cytokine levels in BAL fluid}

To address the mechanism of S-CMC on airway allergic inflammation, the levels of different cytokines in the BAL fluid were determined. As shown in figure 8 , levels of the T-helper (Th)-2 cytokines, IL-4, IL-5, and IL-13, were significantly increased in the BAL fluid $6 \mathrm{~h}$ after secondary allergen challenge compared with saline challenge. These levels were much lower when assayed $72 \mathrm{~h}$ after secondary challenge. The levels of IL-10 were increased after secondary challenge and remained high at $72 \mathrm{~h}$. S-CMC treatment induced further increases in IL-10 levels in BAL fluid at $72 \mathrm{~h}$. The levels of IFN$\gamma$ and IL-12 were increased after secondary allergen challenge and S-CMC treatment further increased the levels of IL-12 at $72 \mathrm{~h}$. Treatment with $S-C M C$ reduced the levels of IL-5 and IL13 at $72 \mathrm{~h}$.

\section{Cytokine levels in cultured cells}

Lung, spleen and PBLN cells were collected and purified from mice after secondary OVA challenge. BAL alveolar macrophages were collected after saline challenge (as described in Material and methods) and cytokine levels in the supernates of cultured cells were determined. The levels of IL-10 were increased in lung cells when cultured with OVA (fig. 9a-c). Levels of IL-10 from spleen and PBLN cells, as well as levels of IL-5 and IL-13, also showed some increase (data not shown). 

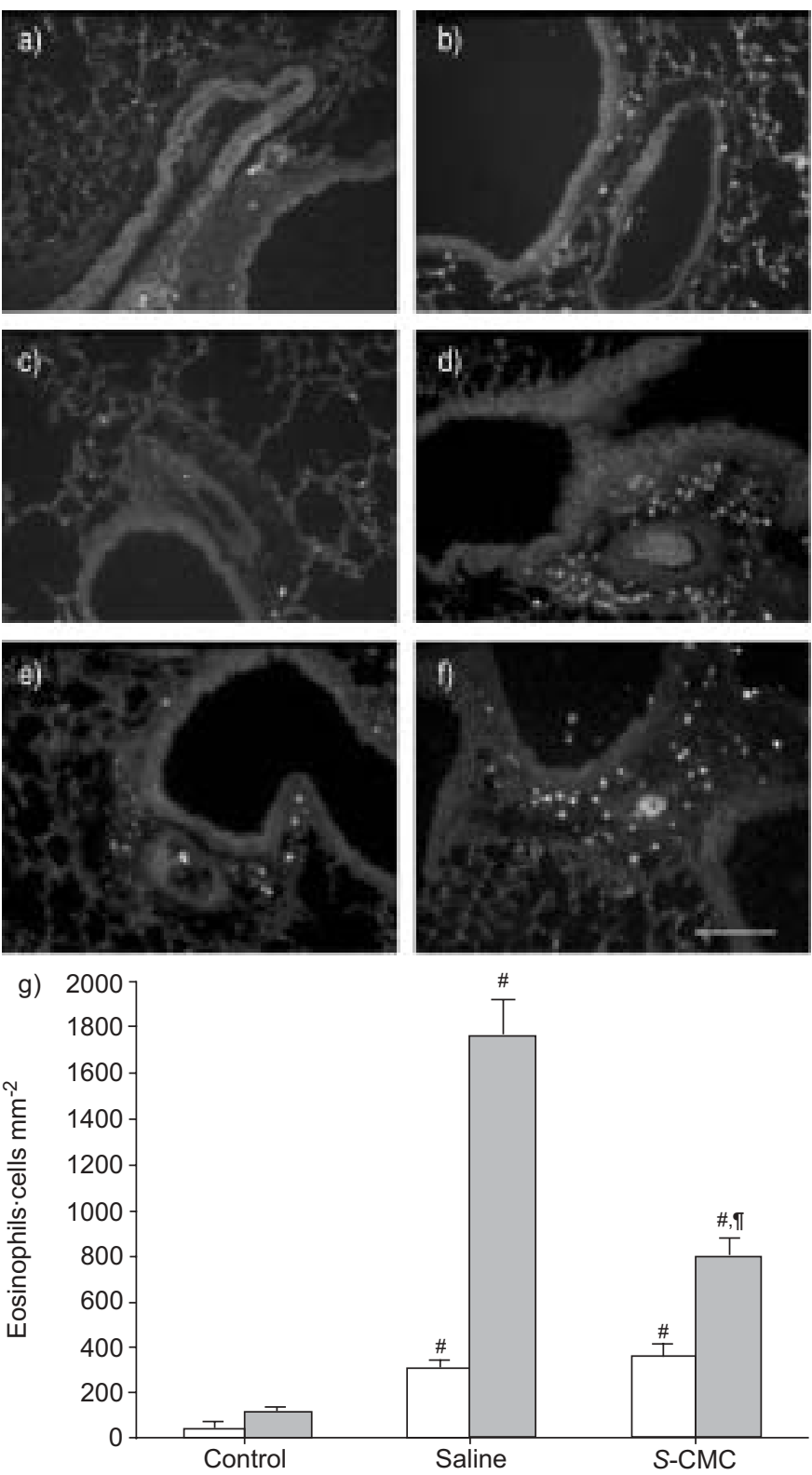

FIGURE 7. Anti-major basic protein (MBP) staining of airways prepared from lungs $6 \mathrm{~h}$ after secondary challenge ( $\mathrm{a}, \mathrm{c}$ and $\mathrm{e}$ ) and $72 \mathrm{~h}$ after secondary challenge $(b, d$ and $f$ ). Saline challenge ( $a$ and $b$ ), secondary allergen challenge following saline treatment (c and $d$ ) and secondary allergen challenge following $S$ carboxymethylcysteine (S-CMC) treatment (e and f). Scale bar=100 $\mu \mathrm{m}$. g) The number of MBP-positive cells after secondary challenge was quantified. $\square$ : after $6 \mathrm{~h}$; 1 : after 72 h. $\mathrm{n}=6$; $\mathrm{S}$-CMC treatment versus vehicle. ${ }^{*}: \mathrm{p}<0.001$ significant difference expressed to saline challenge; 9 : $p<0.001$ significant difference expressed to saline treatment.

However, these increased levels were not altered by inclusion of S-CMC in the cultures. Conversely, the levels of Th-1 cytokines IFN- $\gamma$ and IL-12 in cultured lung cells were markedly increased with S-CMC treatment. These cytokines were not detected in cultures of spleen and PBLN cells (data not shown). In cultures of alveolar macrophage, IFN- $\gamma$, IL-12 and IL-10 were increased with $S$-CMC treatment (fig. 9d-f).

\section{DISCUSSION}

$S$-CMC has been widely used as a mucoregulator, since it is thought to improve mucus clearance by modifying its biochemical characteristics [21]. S-CMC has been used in the treatment of COPD. EDWARDS et al. [9] reported that S-CMC improved the symptoms of COPD patients. S-CMC has been reported to have other therapeutic effects in airway inflammation. For example, S-CMC has been shown to have an antioxidant effect [22] and improves $\mathrm{SO}_{2}$ gas-induced lung inflammation. S-CMC normalised levels of fucose and sialic acid content in mucin glycoprotein and inhibited the increase in expression level of MUC5AC protein in the airway epithelium of rats [23]. S-CMC has been reported to inhibit neutrophil migration in vivo and in vitro [24]. IsHII et al. [14] showed that S-CMC may inhibit neutrophil activity through induction of phosphatidylinositol-specific phospholipase $\mathrm{C}$ in vitro. In asthma, S-CMC has been shown to have some efficacy with improvement of mucociliary transport or suppression of the cough reflex $[25,26]$. However, controlled clinical studies have not been carried out to determine S-CMC efficacy on airway function or airway inflammation.

In the present study, mice developed a two phase airway inflammatory response after secondary allergen challenge, one neutrophilic and the other eosinophilic. AHR to inhaled MCh was detected at both phases of the response to secondary challenge. In the first phase, $6 \mathrm{~h}$ after last antigen challenge, mice developed AHR and a neutrophil-dominant airway inflammatory response with very few eosinophils in the BAL fluid. S-CMC administration improved both AHR and reduced the number of neutrophils in the airway. During this phase, only the higher dose of $S$-CMC appeared effective. In asthma patients [27, 28] and in animal models [15], neutrophils have been shown to be the first inflammatory cells in the airways after allergen challenge. Neutrophils are known to release several chemical mediators known to be toxic to the airways. The timing of the peak neutrophil influx coincided with development of AHR. The issue as to whether neutrophils directly or indirectly contribute to the development of AHR is not clear [16, 29]. Thus, although S-CMC treatment reduced both neutrophil accumulation and AHR, at the present time the two processes cannot be definitely linked.

The response to antigen challenge at $72 \mathrm{~h}$ was quite different and was characterised by a marked increase in numbers of eosinophils accompanied by development of AHR. S-CMC treatment reduced the numbers of eosinophils and virtually abolished AHR, suggesting greater efficacy at this later time point than at $6 \mathrm{~h}$. At $72 \mathrm{~h}$, the response to $S$-CMC showed a clear dose dependency. In part, this greater efficacy at $72 \mathrm{~h}$ compared with $6 \mathrm{~h}$ may reflect the longer duration of S-CMC treatment.

Mice developed a marked cellular infiltration in the peribronchial regions $72 \mathrm{~h}$ after secondary allergen challenge compared with saline-challenged mice. This infiltration was more marked than observed at $6 \mathrm{~h}$. Staining of the lung sections with MBP antibody revealed some eosinophil accumulation (above controls) in the peribronchial regions at $6 \mathrm{~h}$. Treatment with S-CMC had little effect on this response. When eosinophilic infiltration into the peribronchial regions and airway lumen was prominent $72 \mathrm{~h}$ after secondary antigen 

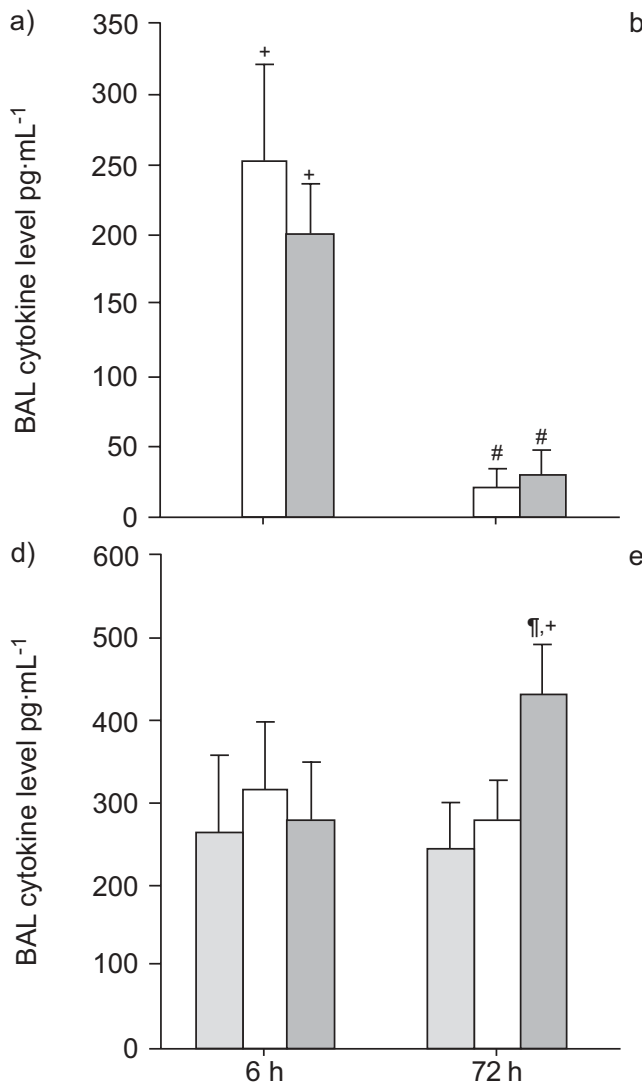

b)

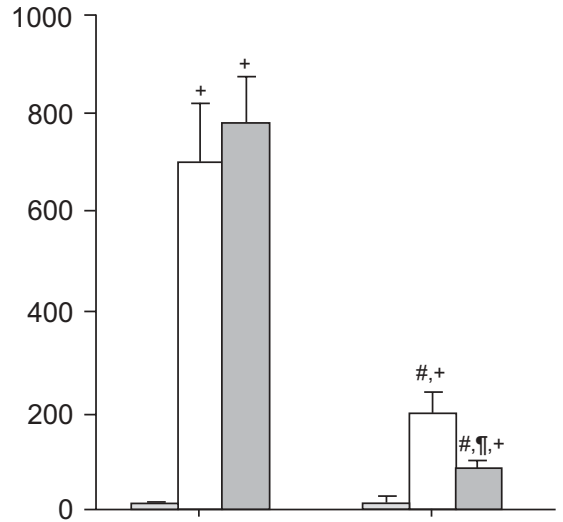

e) 1600

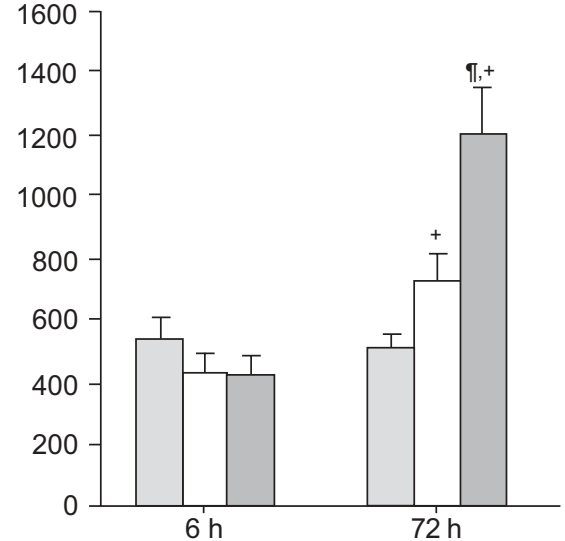

c) 250

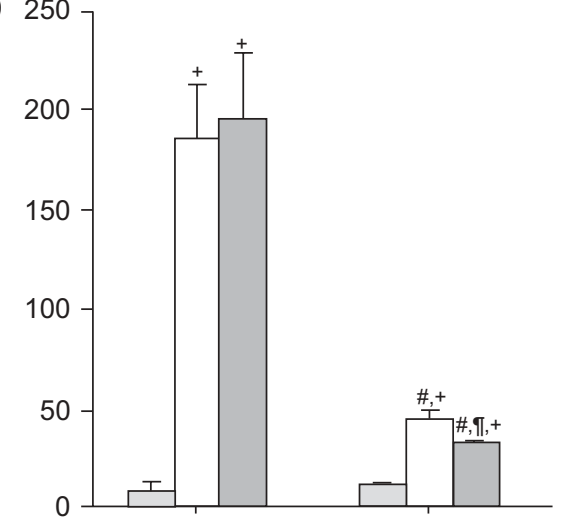

f) 350

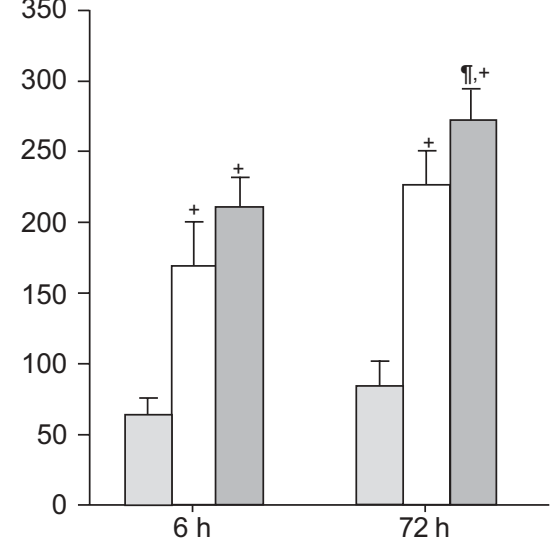

FIGURE 8. Cytokine levels in bronchoalveolar lavage (BAL) fluid in mice receiving saline challenge $(\square)$, secondary allergen challenge following S-carboxymethylcysteine (S-CMC; $\square$ ) or saline treatment ( $\square$ ). a) Interleukin (IL)-4, b) IL-5, C) IL-13, d) interferon- $\gamma$, e) IL-12 and f) IL-10. $n=11-12$ in each group. ${ }^{*}: p<0.05$ significant difference between the $6 \mathrm{~h}$ and $72 \mathrm{~h}$ time points after secondary allergen challenge; ${ }^{\top}: \mathrm{p}<0.05$ significant difference between saline-treated and $S$-CMC-treated groups; ${ }^{+}: \mathrm{p}<0.05$ significant difference between secondary allergen challenge or saline challenge.

challenge, this inflammatory cell influx was significantly reduced by $S$-CMC treatment. Since eosinophils in the airway have been thought to contribute to the development of AHR $[17,30]$, this reduction by $S-C M C$ may account for the normalisation of airway function. To date, no direct effects of $S-C M C$ on eosinophils have been described.

Goblet cell hyperplasia was virtually undetectable $6 \mathrm{~h}$ after secondary antigen challenge, while goblet cell hyperplasia and mucus hyperproduction was markedly increased at $72 \mathrm{~h}$. At $72 \mathrm{~h}, \mathrm{~S}$-CMC treatment was effective in reducing this response which may have contributed to the decrease in AHR [6]. Since mucin-related gene MUC5AC expression has been shown to be upregulated by neutrophil elastase through reactive oxygen species [31], S-CMC may modulate mucus production through this mechanism as reported using $\mathrm{SO}_{2}$ gas-induced lung inflammation [23].

Many of the responses leading to AHR, inflammation and goblet cell hyperplasia are the direct result of changes in specific cytokine levels. When cytokine levels in BAL fluid were determined, an increase in the Th- 2 cytokines, IL-4, IL-5 and IL-13, was detected $6 \mathrm{~h}$ after secondary antigen challenge. In fact, by $72 \mathrm{~h}$ these levels were markedly reduced. S-CMC treatment was virtually ineffective in altering the levels of these cytokines at $6 \mathrm{~h}$. S-CMC showed some efficacy in reducing cytokine levels at $72 \mathrm{~h}$ and at this time point the reduction in IL-13 may explain the decrease in goblet cell hyperplasia [32]. The levels of IL-5 were maximally increased when neutrophils were dominant at $6 \mathrm{~h}$, but decreased by $72 \mathrm{~h}$ (from 700 to $200 \mathrm{pg} \cdot \mathrm{mL}^{-1}$ ) when eosinophils were dominant in the airways. It is known that IL-5 is a potent eosinophil inducer [33], but there may be a time lag for eosinophil induction by IL5. When the temporal association of eosinophils in lung tissue and BAL was examined, eosinophil accumulation in the lung preceded that in the BAL by $\geqslant 24 \mathrm{~h}$ [15], as was shown here.

The levels of IFN- $\gamma$ and IL-12 remained stable at the 6 and $72 \mathrm{~h}$ time points after secondary challenge, and were significantly increased in S-CMC treated mice. The levels of IL-10 were increased at 6 and $72 \mathrm{~h}$ after secondary challenge, and were further increased with $S$-CMC treatment.

The Th-2 cytokines, IL-4, IL-5 and IL-13, have been associated with allergic eosinophilic airway inflammation and AHR in human asthma [29] as well as animal models [30]. However, IFN- $\gamma$ may counteract Th-2 cytokine activities [34]. Administration of IL-12 has been shown to reduce AHR and eosinophilic inflammation [35]. The function of IL-10 is more complex. MAKELA et al. [36] reported that IL-10 is necessary for the development of AHR, while other reports showed that IL10 can regulate allergen-induced airway inflammation [37]. 

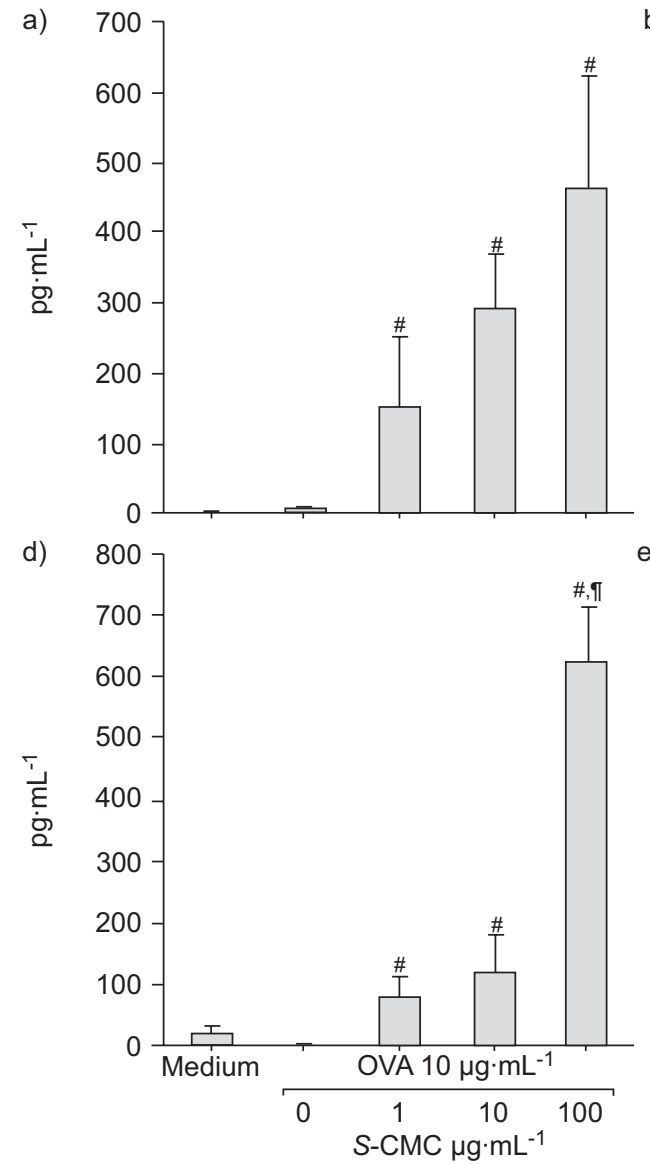

b)

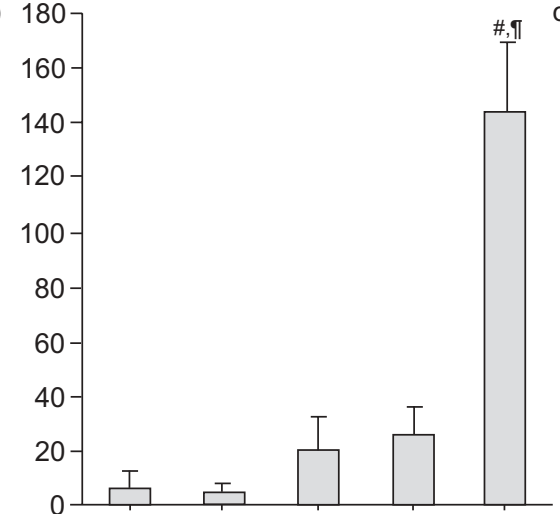

e) 2000

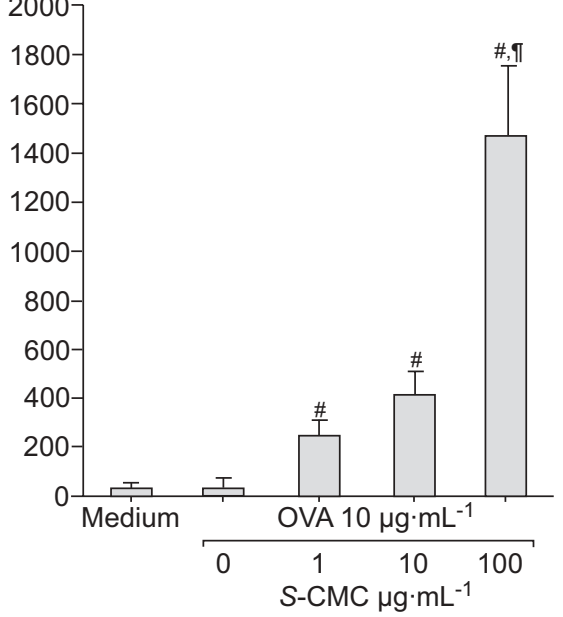

c) 1400

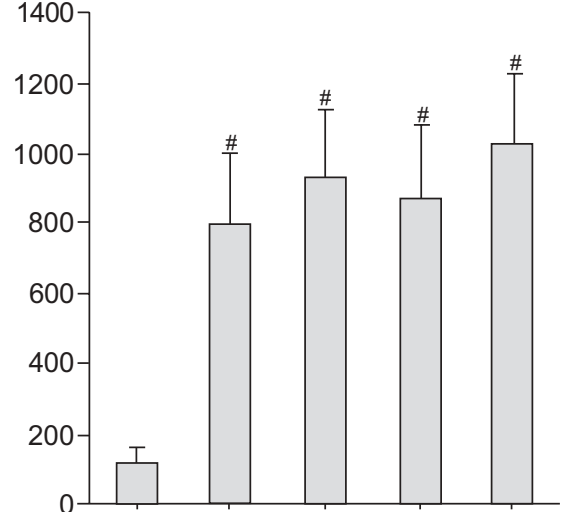

f) 180

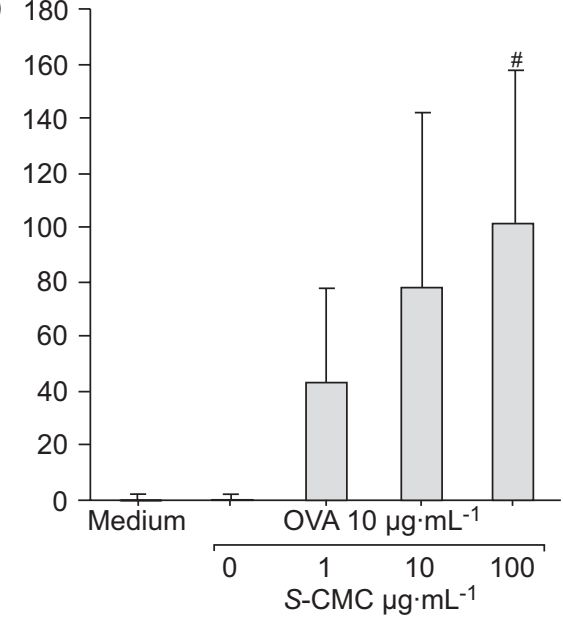

FIGURE 9. Cells were cultured for $24 \mathrm{~h}$ with or without $10 \mu \mathrm{g} \cdot \mathrm{mL}^{-1}$ of ovalbumin (OVA) in the presence of various concentrations of $\mathrm{S}$-carboxymethylcysteine (S-CMC; 0 , 1,10 and $100 \mu \mathrm{g} \cdot \mathrm{mL}^{-1}$ ). a, b, c) Cytokine levels (interferon (IFN)- $\gamma$, interleukin (IL)-12 and IL-10, respectively) in supernates from cultures of isolated lung cells. $\mathrm{d}$, e, f) Cytokine levels (IFN- $\gamma$, IL-12, IL-10, respectively) in supernates of cultured alveolar macrophages. $n=6 . \#: p<0.05$ significant difference versus medium; ${ }^{\text {I: }} p<0.05$ significant difference between S-CMC $100 \mu \mathrm{g} \cdot \mathrm{mL}^{-1}$ and $10 \mu \mathrm{g} \cdot \mathrm{mL}^{-1}$ treatment.

Both IL-10 and IL-12 are secreted mainly by monocytes or macrophages. As IL-10 and IL-12 were shown to be modulated by $S$-CMC treatment in vitro, S-CMC may regulate cytokine production from macrophages or monocytes in vivo as well [24]. The increased levels of IL-10 or IL-12 seen following SCMC treatment may be advantageous for reducing AHR and normalising airway function, and the increases in IFN- $\gamma$ may be more beneficial since IFN- $\gamma$ is recognised as a negative regulator of allergic inflammation in the airways [38].

In summary, administration of the mucoregulator $S$-carboxymethylcysteine was shown to normalise airway hyperresponsiveness. This was accompanied by reducing neutrophils or eosinophils in the airways at the two distinct phases of the response to secondary allergen challenge. S-carboxymethylcysteine also modulated bronchoalveolar lavage fluid cytokine levels and goblet cell hyperplasia. Taken together, in both the neutrophil- and eosinophil-dominant phases of the response to secondary allergen challenge, $S$-carboxymethylcysteine reduced airway hyperresponsiveness to inhaled methacholine indicating the potential for its use as a modulator of the immune/inflammatory response in asthmatics repeatedly exposed to allergens.

\section{REFERENCES}

1 Sly RM. Decreases in asthma mortality in the United States. Ann Allergy Asthma Immunol 2000; 85: 121-127.

2 O'Byrne PM, Inman MD. Airway hyperresponsiveness. Chest 2003; 123: 411S-416S.

3 Larche M, Robinson DS, Kay AB. The role of T lymphocytes in the pathogenesis of asthma. J Allergy Clin Immunol 2003; 111: 450-463.

4 Oshiba A, Hamelmann E, Haczku A, et al. Modulation of antigen-induced $\mathrm{B}$ and $\mathrm{T}$ cell responses by antigen-specific IgE antibodies. J Immunol 1997; 159: 4056-4063.

5 De Sanctis GT, Itoh A, Green FH, et al. T-lymphocytes regulate genetically determined airway hyperresponsiveness in mice. Nature Med 1997; 3: 460-462.

6 Fahy JV, Corry DB, Boushey HA. Airway inflammation and remodeling in asthma. Curr Opin Pulm Med 2000; 6: 15-20.

7 Ordonez CL, Khashayar R, Wong $\mathrm{HH}$, et al. Mild and moderate asthma is associated with airway goblet cell hyperplasia and abnormalities in mucin gene expression. Am J Respir Crit Care Med 2001; 163: 517-523.

8 Kibe A, Inoue H, Fukuyama S, et al. Differential regulation by glucocorticoid of interleukin-13-induced eosinophilia, 
hyperresponsiveness, and goblet cell hyperplasia in mouse airways. Am J Respir Crit Care Med 2003; 167: 50-56.

9 Edwards DF, Steel AK, Scott JK, Jordan JW. S-carboxymethylcysteine in the fluidification of sputum and treatment of chronic airway obstruction. Chest 1976; 70: 506-513.

10 Ohashi Y, Nakai Y, Sugiura Y, Ohno Y, Okamoto H, Hayashi M. Effect of S-carboxymethylcysteine on ciliary activity in chronic sinusitis. Rhinology 1993; 31: 107-111.

11 Moore RA, Commins D, Bates G, Phillips CJ. S-carboxymethylcysteine in the treatment of glue ear: quantitative systematic review. BMC Fam Pract 2001; 2: 3.

12 Katayama N, Fujimura M, Ueda A, et al. Effects of carbocysteine on antigen-induced increases in cough sensitivity and bronchial responsiveness in guinea pigs. $J$ Pharmacol Exp Ther 2001; 297: 975-980.

13 Asti C, Melillo G, Caselli GF, et al. Effectiveness of carbocysteine lysine salt monohydrate on models of airway inflammation and hyperresponsiveness. Pharmacol Res 1995; 31: 387-392.

14 Ishii Y, Kimura T, Morishima Y, et al. S-carboxymethylcysteine inhibits neutrophil activation mediated by $\mathrm{N}$-formylmethionyl-leucyl-phenylalanine. Eur J Pharmacol 2002; 449: 183-189.

15 Tomkinson A, Cieslewicz G, Duez C, Larson KA, Lee JJ, Gelfand EW. Temporal association between airway hyperresponsiveness and airway eosinophilia in ovalbuminsensitized mice. Am J Respir Crit Care Med 2001; 163: 721-730.

16 Taube C, Nick JA, Siegmund B, et al. Inhibition of early airway neutrophilia does not affect development of airway hyperresponsiveness. Am J Respir Cell Mol Biol 2004; 30: 837-843.

17 Kanehiro A, Ikemura T, Makela MJ, et al. Inhibition of phosphodiesterase 4 attenuates airway hyperresponsiveness and airway inflammation in a model of secondary allergen challenge. Am J Respir Crit Care Med 2001; 163: 173-184.

18 Takeda K, Hamelmann E, Joetham A, et al. Development of eosinophilic airway inflammation and airway hyperresponsiveness in mast cell-deficient mice. J Exp Med 1997; 186: 449-454.

19 Rha YH, Taube C, Haczku A, et al. Effect of microbial heat shock proteins on airway inflammation and hyperresponsiveness. J Immunol 2002; 169: 5300-5307.

20 Takeda K, Haczku A, Lee JJ, Irvin CG, Gelfand EW. Strain dependence of airway hyperresponsiveness reflects differences in eosinophil localization in the lung. Am J Physiol Lung Cell Mol Physiol 2001; 281: L394-L402.

21 Houtmeyers E, Gosselink R, Gayan-Ramirez G, Decramer M. Effect of drugs on mucus clearance. Eur Respir J 1999; 14: 452-467.

22 Brandolini L, Allergretti M, Berdini V, et al. Carbocysteine lysine salt monohydrate (SCMC-LYS) is a selective scavenger of reactive oxygen intermediates (ROIs). Eur Cytokine Network 2003; 14: 20-26.

23 Ishibashi Y, Kobayashi F, Idesawa A, Taniguchi A, Matsuzawa S. Effects of carbocysteine on altered activities of glycosidase and glycosyltransferase and expression of
Muc5ac in SO2-exposed rats. Eur J Pharmacol 2004; 687: 7-15.

24 Hirata Y, Ohashi M. Effects of S-carboxymethylcysteine (SCMC) on bleomycin-induced lung injury in mice. Kiso to Rinsho 1995; 29: 3661-3666.

25 Solopov VN, Lunichkina IV, Plisko LF, Kolganova NA. Effect of mukodin on indices of mucociliary transport. Ter Arkh 1988; 60: 55-57.

26 Ishiura Y, Fujimura M, Yamamori C, et al. Effect of carbocysteine on cough reflex to capsaicin in asthmatic patients. Br J Clin Pharmacol 2003; 55: 504-510.

27 Koh YY, Dupuis R, Pollice M, Albertine KH, Fish JE, Peters SP. Neutrophils recruited to the lungs of humans by segmental antigen challenge display a reduced chemotactic response to leukotriene B4. Am J Respir Cell Mol Biol 1993; 8: 493-499.

28 Nocker RE, Out TA, Weller FR, Mul EP, Jansen HM, van der Zee JS. Influx of neutrophils into the airway lumen at $4 \mathrm{~h}$ after segmental allergen challenge in asthma. Intl Arch Allergy Immunol 1999; 119: 45-53.

29 Wardlaw AJ, Brightling CE, Green R, Woltmann G, Bradding P, Pavord ID. New insights into the relationship between airway inflammation and asthma. Clin Sci (Lond) 2002; 103: 201-211.

30 Hamelmann E, Wahn U, Gelfand EW. Role of the Th2 cytokines in the development of allergen-induced airway inflammation and hyperresponsiveness. Intl Arch Allergy Immunol 1999; 118: 90-94.

31 Fischer BM, Voynow JA. Neutrophil elastase induces MUC5AC gene expression in airway epithelium via a pathway involving reactive oxygen species. Am J Respir Cell Mol Biol 2002; 26: 447-452.

32 Wills-Karp M, Luyimbazi J, Xu X, et al. Interleukin-13: Central mediator of allergic asthma. Science 1998; 282: 2258-2261.

33 Lopez AF, Sanderson CJ, Gamble JR, Campbell HD, Young IG, Vadas MA. Recombinant human interleukin 5 is a selective activator of human eosinophil function. J Exp Med 1988; 167: 219-224.

34 Szabo SJ, Sullivan BM, Peng SL, Glimcher LH. Molecular mechanisms regulating Th1 immune responses. Annu Rev Immunol 2003; 21: 713-758.

35 Schwarze J, Hamelmann E, Cieslewicz G, et al. Local treatment with IL-12 is an effective inhibitor of airway hyperresponsiveness and lung eosinophilia after airway challenge in sensitized mice. J Allergy Clin Immunol 1998; 102: 86-93.

36 Makela MJ, Kanehiro A, Borish L, et al. IL-10 is necessary for the expression of airway hyperresponsiveness but not pulmonary inflammation after allergic sensitization. Proc Natl Acad Sci USA 2000; 97: 6007-6012.

37 Tournoy KG, Kips JC, Pauwels RA. Endogenous interleukin-10 suppresses allergen-induced airway inflammation and nonspecific airway responsiveness. Clin Exp Allergy 2000; 30: 775-783.

38 Tang C, Inman MD, van Rooijen $\mathrm{N}$, et al. Th type 1-stimulating activity of lung macrophages inhibits Th2mediated allergic airway inflammation by an IFN-gammadependent mechanism. J Immunol 2001; 166: 1471-1481. 